\title{
Psychosocial outcome following spinal cord injury
}

\author{
K R Whalley Hammell MSc OT(C) DipCOT. \\ (Formerly) Rehabilitation Research Unit, University of Southampton, Southampton, \\ England.
}

Studies have indicated that loss of social contact remains the primary complaint of people with head injuries many years after discharge. In an attempt to disentangle specific and nonspecific effects of head injury a study was undertaken to compare a group of 15 men with severe closed head injuries and their wives, with a group of 15 men with complete, traumatic spinal cord injuries and their partners $(n=60)$. Time since discharge extended from 4 months to several years. This paper focuses primarily upon the results and implication of the responses from the group of men with spinal cord injuries and their partners.

The Interview Schedule for Social Interaction was correlated with the Leeds Scale for the Self Assessment of Anxiety and Depression. All groups reported low availability and adequacy of social integration and exhibited high levels of depression. The group of men with spinal cord injuries had the lowest scores for the availability of social integration, indicating that the social isolation which has previously been identified amongst people with head injuries may not be attributable solely to brain damage. ${ }^{1}$

Keywords: spinal cord injuries; head injuries; psychological outcome; social outcome; quality of life; rehabilitation.

\section{Introduction}

Assessment of outcome following rehabilitation could reasonably be expected to include some measure of the quality of life which has been saved. However, outcome measurement has traditionally focused predominantly upon the assessment of physical skills. Successful and fulfilling adult functioning requires more than mobility and self care skills, it also requires the ability and opportunity to interact socially.

The present study sought to explore the availability and adequacy of social support following central nervous system trauma and the relationship of this to emotional distress. This was viewed as being a key indicator to the quality of life and satisfaction with life following severe traumatic injury, and thus to the success of the rehabilitation process. ${ }^{1}$

Many studies have highlighted the importance of social support in attenuating the

Correspondence: Box 515, Oxbow, Saskatchewan, S0C 2B0, Canada. effects of events which are stressful, hence reducing the incidence of disease or morbidity. ${ }^{2-4}$ It has also been noted that such support is linked to improved adaptation to especially stressful circumstances, such as adjustment to a physical incapacity. ${ }^{5}$ One of the few studies to examine the availability of social support for people with physical disabilities found that in the presence of adverse life events, a low level of social contact was associated with deterioration in psychosocial and emotional functioning. ${ }^{6,7}$ Recent studies have identified the influence of supportive interpersonal relationships upon adjustment to spinal cord injury (SCI). ${ }^{8,9}$ Researchers have also indicated that social support is positively associated with life satisfaction and physical wellbeing following spinal cord injury; whilst satisfaction with social support is found to be associated negatively with depressive symptomatology. ${ }^{10}$

Social isolation has been identified as a long term problem for people who have sustained severe head injuries (HI). ${ }^{11-14}$ 
However, the sequelae of a severe HI will be a mixture of those effects specific to the brain injury and more general effects due to reaction to trauma, hospitalisation, adaptation to disability and social stigmatisation. The present study compared a group of men with severe HI with a group of men with complete SCI. McKinlay \& Brooks ${ }^{15}$ propose that both groups are drawn from similar 'at risk' populations (predominantly young men) who have sustained major traumatic injury, resulting in sudden hospitalisation, prolonged hospitalisation and leading to significant and irreversible disability. Recent study of psychosocial functioning also compared a group of men with closed HI with men who had sustained SCI. ${ }^{16}$ The critical assumption was that the groups are epidemiologically similar and that it is random (accident related) mechanical trauma which determines the level of central nervous system lesion, whether this is intracranial or spinal cord. Whilst groups of men with SCI have been compared to men with $\mathrm{HI}$ in several studies ${ }^{17-19}$ McKinlay $\&$ Brooks $^{15}$ outline the disadvantages of using a SCI comparison group, particularly the suggestion made by Hohmann ${ }^{20}$ that higher spinal cord lesions may have a direct, dulling effect upon emotional reactions. However, this theory has been refuted in subsequent studies. ${ }^{21-25}$

It has been noted that SCI poses great adaptation demands both on injured persons and on significant others living with them. ${ }^{26}$ Further, researchers have indicated that men with HI and SCI rely heavily and predominantly upon spouses for social support ${ }^{14,26,27}$ and that a significant level of psychological distress and social isolation may be experienced by these carers. ${ }^{28,29}$ Whilst it is frequently acknowledged that spouses play a major role in the rehabilitation process, there is little published research on the spouses' long term adjustment to living with a partner who has a SCI..$^{30}$

The present study was designed to investigate the availability and perceived adequacy of social support for couples where one has sustained either a head or spinal cord injury. This was examined in relation to the levels of anxiety and depression expressed by each individual.
This paper will focus predominantly upon the results and implications of the responses provided by the men with SCI, and their partners.

\section{Methodology}

\section{Subjects}

In order to reduce the number of variables under study, all injured persons were male. This reflects the incidence of both closed HI and SCI and was a response to studies which suggest that men and women respond differently to the onset of traumatic disability. ${ }^{31}$ Subjects were included if they were living at home with their partner both before their injury and at the time of the study.

The age range for the study was established as 20-59 years. This allowed for inclusion of couples at various stages of their relationships but excludes the older age groups where other variables might exert compounding influences.

To be eligible for inclusion in the study, all men with $\mathrm{HI}$ had sustained severe or very severe head injuries, causing unconsciousness for $6 \mathrm{~h}$ or more, or post traumatic amnesia for at least $24 \mathrm{~h}$. Head injury has been reported to occur in $10 \%-60 \%$ of patients with SCI. ${ }^{32-34}$ Medical records of patients with SCI were examined for documentation of loss of consciousness, post traumatic amnesia or other evidence of HI. No subject was included if he had sustained a HI in addition to his SCI. SCI subjects had sustained nonprogressive, traumatic injuries which produced either complete lesions, or incomplete lesions which resulted in a significant degree of physical impairment. All SCI subjects were wheelchair users. Injured men were identified either from consecutive discharge records (SCI) or from a HI research team and clinical psychologist (HI). Fifty couples were contacted, of whom $60 \%$ agreed to participate in the study: 15 men with $\mathrm{HI}$ and their wives and 15 men with SCI and their wives or partners $(n=60)$. No demographic differences were apparent between the subjects included in the study and those who did not wish to participate.

All subjects included in the study had 
been living in the community for at least 4 months since discharge.

\section{Demographic information}

Demographic information was obtained concerning age, marital status, age at injury, weeks of formal rehabilitation, level of education, employment status (past and present), months since injury, months since discharge and availability of transportation.

At the time of study, the mean age for the men with $\mathrm{HI}$ was 41.7 . For the men with SCI the mean age was 40.0 .

Mean age at injury was 37 for both groups of men, which is higher than the usual aetiologies for these injuries. This reflects the inclusion requirement for stable partnerships existing before and after injury.

The men with SCI had sustained a total of 14 complete and two incomplete lesionsone man having an incomplete cervical lesion in addition to a complete thoracic lesion. Injury levels were from C4 to T12.

It had been anticipated that people with SCI might have experienced reduced opportunities for social participation due to transportation problems. In reality, every individual in the study $(n=60)$ had access to private transportation.

Twenty-nine of the 30 couples were married. One couple had been living together in a common law relationship both before and after the man sustained a SCI. The men with SCI had been living at home for between 6 and 62 months.

\section{Measure of social support}

The Interview Schedule for Social Interaction (ISSI) ${ }^{35,36}$ was chosen as the dependent variable to assess social support. This research instrument assesses the availability and supportive quality of social relationships. The ISSI has been used successfully by other researchers with HI subjects ${ }^{14,37}$ and SCI subjects. ${ }^{38}$ The ISSI has been tested for reliability, internal consistency and test/retest stability ${ }^{35,39}$ and is considered to have validity. ${ }^{35,40}$ It has been determined that a personal interview for the ISSI is essential $^{41}$ and this was the procedure fol- lowed in this study. All subjects were interviewed by the same person.

Four main scores are calculated for each respondent.

'AVAT' - the, availability of attachment (8 items).

'ADAT'-the perceived adequacy of attachment. The perceived adequacy of an attachment can only be assessed if a respondent has identified an available attachment. The ADAT score is thus identified by a percentage. That is, the percentage of the number of 'adequacy' questions the respondent could be asked (maximum 12 items).

'AVSI' - the availability of social integration (16 items).

'ADSI' - the perceived adequacy of social integration (17 items).

\section{Self rating scale of psychological distress}

Self rating scales have frequently been used in psychiatric practice and research and many such scales have proved to be valid measures of the severity of certain psychiatric disorders, ${ }^{42}$ including amongst people with HI. ${ }^{43}$

The Leeds Scale for the Self Assessment of Anxiety and Depression ${ }^{42,44}$ was chosen because of the following features. It has well demonstrated reliability and validity. Population norms exist and the scale has high acceptability in the community. ${ }^{43,45}$ It is quick to complete, allows for self report, scores can be corrected to prevent significant correlation with age and no items are included which are liable to result in sex bias. It has been used in previous studies concerning closed head injury. ${ }^{43,45-48}$ It was recognised that the statement 'I find it easy to do the things I used to do' would be likely to produce a biased result among SCI men. Allowance was therefore made for this physical (rather than psychological) effect in the data analysis.

\section{Data analysis}

Analysis was undertaken using the Statistical Package for the Social Sciences (SPSSS). 


\section{Results}

\section{Demographic results}

Mann-Whitney $U$ and $\chi^{2}$ tests were performed on all demographic data to determine whether there was a significant difference in distributions between two groups. The two groups of injured men were compared to each other, as were the two groups of partners.

Although the two groups of men had originally been matched only in terms of sex, age range and relationship status, it was found that there was only one statistically significant difference between the demographic variables. Response rates were also similar. Subjects were visited in a wide geographic area, in a mixture of urban and rural communities in Southern England and amongst mixed socioeconomic situations.

There was one statistically significant difference between the two groups, concerning the number of weeks of rehabilitation $(p=0.0061)$. All the men with SCI received their rehabilitation at a specialised spinal unit, although this is not the universal experience of people with acute spinal cord lesions in the UK. Among the men with severe $\mathrm{HI}$, the most common number of weeks of rehabilitation was zero.

All 30 men had been gainfully employed at the time of their injuries. However, 18 of the 30 men $(60 \%)$ were unemployed at the time of the study. Among men with SCI, eight $(53 \%)$ were unemployed, with five men employed part time and one undertaking further education, part time. Only one of the spinal cord injured group was in full time employment, whilst five of the men with severe head injuries were employed on a full time basis.

It had been anticipated that the lack of a suitable wheelchair for outdoor use might have a negative impact upon the opportunities for social activities by the men with SCI. In reality, 14 of these men had discarded their heavy, government issued chairs and had purchased their own ultra-light wheelchairs or modern power chairs to enable enhanced community access. The one individual who used the wheelchair with which he had originally been issued left his house only two or three times a year.

\section{Social support score results}

As anticipated among a sample of people who had partners, AVAT scores were high (median $=7$ ) for all groups. Median ADAT\% scores were over $80 \%$ for all four groups, with all men with SCI and all their partners nominating at least two people as being sources of close support.

The median scores for the availability of social integration (AVSI) were remarkably similar for all four groups - but were all low. Social support scores of partners were found to mirror those of the injured person. The social isolation of people with head injuries which has been reported by other researchers ${ }^{11-14,37}$ was not found to be exclusive to head injury in this study. Indeed, the lowest scores for social integration were reported by men with spinal cord injuries. All four groups had similar ADSI scores.

\section{Leeds Anxiety Scale}

All anxiety scores were adjusted for age. Whilst six of the men with HI (40\%) and six of their wives $(40 \%)$ demonstrated clinically significant levels of anxiety, the mean anxiety score for men with SCI was 4.3 and for their wives was 3.67. (A score greater than 6 is regarded as providing the most satisfac-

Table I Summary of results

\begin{tabular}{lcccc}
\hline & $\begin{array}{c}\text { AVSI } \\
(\max =16) \\
\text { mean score }\end{array}$ & $\begin{array}{c}\text { ADSI } \\
(\max =17) \\
\text { mean score }\end{array}$ & Anxiety & Depression \\
\hline HI men $(n=15)$ & 7.80 & 10.6 & 6 & 8 \\
HI wives $(n=15)$ & 8.13 & 10.8 & 6 & 7 \\
SCI men $(n=15)$ & 6.73 & 11.2 & 3 & 5 \\
SCI wives $(n=15)$ & 8.87 & 12.6 & 1 & 5 \\
\hline
\end{tabular}


tory division between healthy and sick populations). Comparison of scores between groups revealed that the wives of men with HI were significantly more anxious than the partners of the men with SCI $(p=0.011)$. It has been suggested elsewhere $^{18}$ that lower levels of anxiety among the wives of men with SCI is due in part to the emotional support which may be provided by these men. This element may be lacking for the wives of men with $\mathrm{HI}$ who may need to assume additional roles and responsibilities without the opportunity to consult with their partners in decision making.

Correlation tests showed that anxiety increased as AVSI and ADSI scores decreased for the men with HI $(p<0.05)$. For their wives, anxiety increased as their perceived adequacy of attachment (ADAT) decreased $(p=0.015)$.

The men with SCI had shown low levels of anxiety and there was no correlation with levels of social support. This tolerance to low levels of social integration may be due to a recognition of the realities of environmental barriers in society. All men with SCI commented that lack of access prohibited their full participation in society. This may contrast with the men with head injuries, who were aware that their lack of social integration was due to internal, personality and cognitive factors rather than to external, environmental barriers.

The partners of the men with SCI showed an inverse relationship between anxiety and perceived adequacy of social integration (ADSI). However, this should be interpreted in the light of the low levels of anxiety that were found among this grouponly one person scored above 6 on the Leeds Scale. Similarly, only two women had low ADSI scores (scores $<9$ ).

\section{Leeds Depression Scale}

Depression scores were adjusted by a factor of -2 for the men with SCI to allow for an exaggerated response to one question due to physical limitations.

No statistically significant differences were found between the four groups on the depression score. In total, 25 of the 60 subjects showed clinically significant levels of depression-including five of the men with SCI and five of their wives. These 10 individuals represent nine couples, hence both partners were depressed in only one couple. However, nine of the 15 partners of men with SCI showed low levels of depression, with scores less than, or equal to 3 . (Scores of 7 and above are taken to represent abnormally elevated levels of depression.)

The current findings are at variance with previous studies in Israel and Canada, ${ }^{16,17}$ in which men with $\mathrm{HI}$ and their wives were found to experience significantly more depression and social isolation than did groups of men with SCI and their wives. The present study in contrast indicates that the lowest levels of social integration were found among the group of men with spinal cord injuries and emphasises the societal and cultural dependence of this kind of study with concomitant dangers of attempts to generalise.

Rank correlations found the AVSI and ADSI scores to be closely related to both anxiety and depression for the men with HI. Data from the wives of these men showed strong, inverse rank correlations between all four indices of social support and depression $(p<0.05)$. This supports the proposition that symptoms of neurosis emerge when people consider themselves to be deficient in some aspects of social relationships. ${ }^{40}$ However, depression was not found to be related to levels of social support in the groups of men with SCI or their partners, in contrast to other studies. ${ }^{38,49}$

Results of the analysis of correlation indicate that the four scores of social support are remarkably similar and that comparison of anxiety and depression scores between groups showed only one significant difference. However, the correlations between these scores are markedly different, and difficult to interpret.

It was recognised that any significant results found from the analysis of scores could be due to a multitude of factors. Length of time since discharge, age, employment status or other demographic variables could be some of the factors which alone, or in combination, might have an 
impact upon achieved results. The stepwise technique of multiple regression was employed to examine independent demographic variables and their relationship to the social and mood scores. None of the independent variables was found to have had a significant influence upon either the social support or mood scores.

\section{Discussion}

The Leeds Scale for the Self Assessment of Anxiety and Depression was found to be less than ideal for use with people who have physical disabilities. A more useful tool could be the Irritability, Depression and Anxiety (IDA) Scale ${ }^{50}$ which has been used satisfactorily with a group of people who are ventilator dependent tetraplegics ${ }^{25}$ and contains no items which are impacted by physical rather than psychological state.

Despite the fact that all men with SCI in this study had attended a specialised treatment unit and received regular follow up, they were not significantly less depressed or anxious than their HI counterparts, nor did they experience higher levels of social integration. It would be interesting to initiate further study to determine whether there are differences in social integration or mood between men with SCI who have attended a specialised treatment unit, and those who have not. It would also be valuable to examine more closely the influence of the environment upon opportunities for social integration for people with SCI.

A study of psychosocial outcome helps to map the effects of the rehabilitation process. It is a cause for concern that all four groups of people reported low levels of social integration. Of particular concern is the finding of clinically significant levels of depression in $41 \%$ of the subjects. It would appear that 'quality of life' in its broadest sense has not yet been achieved but that the repercussions of a traumatic injury extend long after discharge from hospital.

Outcome measures which seek to gauge the impact and effectiveness of rehabilitation interventions have commonly been expressed in terms of physical, functional achievements. ${ }^{51-55}$ Such superficial indicators can mask the considerable difficulties which may continue to prevent quality living for the individual, such as full social and community integration, fulfilling relationships, engagement in meaningful occupation and mental health. ${ }^{56}$ Further, since rehabilitation professionals tend to treat what they measure, assessment of outcome which is based upon the physical skills of the individual may preclude examination of external, environmental factors which may prevent successful community reintegration and adaptation to life in an altered form.

The current study indicates the need to include the spouses of injured men throughout the rehabilitation process. Spouses frequently experience exclusion from the rehabilitation process yet at discharge they may become responsible for ongoing care and continuation of the rehabilitation process. ${ }^{57}$

'All the attention at [the spinal unit] is on helping the spinal cord injured person to cope. There is nothing for the partner or friends. At that stage you are told you can ask questions-but you don't even know what questions to ask.'

Counselling services would appear to be needed on a long term basis for injured men and their partners. This would require assessment during regular follow up, since studies have shown that it is not possible to predict during hospitalisation who is likely to experience the greatest psychiatric and social dysfunction following discharge. ${ }^{47,57}$

Participation in community peer support groups was mentioned by several subjects as being a welcome opportunity to share experiences with others in the same situation. Such contact can easily be facilitated during the rehabilitation process.

Men with SCI face environmental and attitudinal barriers to community integration. Just as men with $\mathrm{HI}$ may require a relearning of social skills in order to interact successfully with other people, several of the subjects with SCI stated that following the onset of their physical disabilities, they had needed to learn how to initiate and maintain comfortable social contact with other people. It is suggested that the rehabilitation team has a role in assisting these individuals to acquire additional social skills 
and techniques to enhance comfortable social interaction..$^{58,59}$

It has been proposed that quality of life is a product of the interaction of personal attributes and resources with environmental resources. ${ }^{60}$ This study has been unable to correlate any number of personal demographic or social support variables with the high levels of depression and social isolation experienced by the men with SCI. This may indicate the need to develop interventions on social and environmental levels to yield improvements in quality of life for people with SCI. ${ }^{60}$ It has become apparent to many researchers that the factors which conspire to create handicap and social disadvantage are not solely the results of any personal, physical limitations but are the consequences of a disabling environment. ${ }^{61,62}$ Jongbloed \& Crichton ${ }^{61}$ suggest that rehabilitation professionals have an inauspicious record in the struggle for removal of architectural and social barriers which prevent full social participation for the client population as a collective group. Perhaps it will be intervention in this larger arena which will produce the most positive outcomes in the future.

\section{Conclusion}

In conclusion, this study has indicated that the social isolation which has been identified amongst people with HI by other researchers may not all be attributable solely to brain damage but may be common to reople with other forms of severe trauma.

The main findings of the study indicate that there were no statistically significant differences for the indices of social support between the men with closed $\mathrm{HI}$, their wives, the men with SCI or their wives or partners. However, whilst anxiety and depression were strongly linked to the indices of social integration for both the men with $\mathrm{HI}$ and their partners, there was no such relationship demonstrated amongst men with SCI or their partners. High levels of depression were found amongst all four groups of people. Injured subjects in this study were marginalised by their poor social integration and their high rate of unemploy- ment. This isolation, and the high levels of depression were shared by their spouses.

The small size of this study $(n=60)$ enables trends to be identified but prevents generalisation to a wider population. The subjects in this study differ from the majority of people with central nervous system trauma on the basis of some demographic factors; that is, age and marital status. Other factors may have been affected by these variables, so that the group under study might have different socioeconomic situations, psychological stability and social supports from subjects in other studies. Thus, although married men with head and spinal cord injuries have been underrepresented in the literature to date, the results of the current study may not be generalisable to the wider population of people with central nervous system trauma.

However, with respect to the population in this study, it was found that men with SCI reported the lowest levels of social intergration and that this was not related to the length of time since discharge. 'Social intergration' incorporates contacts with friends, colleagues, acquaintances and others. Unemployment levels were high for both groups of men.

Forty-one percent of the 60 subjects reported clinically significant levels of depression. This was not related to the length of time since discharge and did not correlate with any of the demographic factors or social indices for either the men with SCI or their partners. Further study is required to investigate which factors are influential in producing depression among this client group.

In planning to meet the needs of people with traumatic neurological injuries and their partners, it is recommended that full regard be made of emotional and social factors, both during comprehensive inpatient rehabilitation and during ongoing community support, following discharge.

\section{Acknowledgements}

The author gratefully acknowledges the support and advice of Sandra Horn and Ann Ashburn of the Rehabilitation Research Unit, University 
of Southampton, and the valuable assistance provided by Mark Mullee, Department of Medical Statistics and Computing, University of Southampton. She also wishes to thank the people who were the subjects for this study and who participated both thoughtfully and enthusiastically, and the consultants who graciously granted access to their patients.

\section{References}

1 Whalley Hammell KR (1991) An investigation into the availability and adequacy of social relationships following head injury and spinal cord injury: a study of injured men and their partners, Unpublished Master of Science thesis (Rehabilitation Studies), University of Southampton.

2 Nuckolls KB, Cassel J, Kaplan BH (1972) Psychosocial assets, life crisis and the prognosis of pregnancy. Am J Epidemiol 95: 431-441.

3 Broadhead WE, Kaplan BH, James SA et al (1983) The epidemiologic evidence for a relationship between social support and health. Am J Epidemiol 117: 521-537.

4 McDowell I, Newell C (1987) Social health. In McDowell I \& Newell C, editors. Measuring Health-a Guide to Rating Scales and Questionnaires. Oxford University Press, Oxford.

5 Bloom JR (1990) The relationship of social support and health. Soc Sci Med 30: 635-637.

6 Patrick DL, Morgan M, Charlton JR (1986) Psychosocial support and change in health status of physically disabled people. Soc Sci Med 22: 1347-1354.

7 Morgan M (1989) Social ties, support and well being. In Patrick DL \& Peach H, editors. Disablement in the community. Oxford Medical Publications, Oxford.

8 Judd FK, Webber JE, Brown DJ et al (1991) Psychological adjustment following traumatic spinal cord injury: a study using the Psychosocial Adjustment to Illness Scale. Paraplegia 29: 173-179.

9 Elliott T, Herrick S, Witty $\mathrm{T}$ et al (1992) Social support and depression following spinal cord injury. Rehabil Psychol 37: 37-48

10 Rintala DH, Young ME, Hart KA et al (1992) Social support and the well-being of persons with spinal cord injury living in the community. Rehabil Psychol 37: 155-163.

11 Thomsen IV (1984) Late outcome of very severe blunt head trauma: a 10-15 year second follow up. J Neurol, Neurosurg Psychiatry 47: 260-268.

12 Oddy M, Humphrey M, Uttley D (1978) Subjective impairment and social recovery after closed head injury. J Neurol Neurosurg Psychiatry 41: 611-616.

13 Weddell R, Oddy M, Jenkins D (1980) Social adjustment after rehabilitation: a two year follow up of patients with severe head injury. Psychol Med 10: 257-263.

14 Kinsella G, Ford B, Moran C (1989) Survival of social relationships following head injury. Int Disabil Stud 11: 9-14.

15 McKinlay WW, Brooks DN (1984) Methodological problems in assessing psychosocial recovery following severe head injury. J Clin Neuropsychol 6: 87-99.

16 Stambrook M, Moore AD, Peters LC et al (1991) Head injury and spinal cord injury: differential effects on psychosocial functioning. J Clin Exp Neuropsychol 13: 521-530.

17 Rosenbaum M, Najenson T (1976) Changes in life patterns and symtoms of low mood as reported by wives of severely brain injured soldiers. J Consult Clin Psychol 44: 881-888.

18 Florian V, Katz S, Lahav V (1989) Impact of traumatic brain damage on family dynamics and functioning: a review. Brain Injury 3: 219-233.

19 Liss M, Willer B (1990) Traumatic brain injury and family relationships: a literature review. Int J Rehabil Res 13: 309-320.

20 Hohmann GW (1966) Some effects of spinal cord lesions on experienced emotional feelings. Psychophysiology 3: $143-156$.

21 Hester G (1971) Effects of functional transection of the spinal cord on task performance under varied emotional conditions. Psychophysiology 8: 451-461.

22 Nestoros JN, Demers-Desrosiers LA, Dalicandro LA (1982) Levels of anxiety and depression in spinal cord injured patients. Psychomatics 23: 823-830.

23 Lowe J, Carroll D (1985) The effects of spinal injury on the intensity of emotional experience. Br J Clin Psychol 24: 135-136.

24 Bermond B, Scheurman J, Nieuwenhuijse B et al (1987) Spinal cord lesions: coping and mood states. Clin Rehabil 1: 111-117.

25 Glass CA (1993) The impact of home based ventilator dependence on family life. Paraplegia 31: 93-101.

26 Decker SD, Schulz R, Wood D (1989) Determinants of well-being in primary care givers of spinal cord injured persons. Rehabil Nurs 14: 6-8.

27 Frank RG, Haut AE, Smick M et al (1990) Coping and family functions after closed head injury. Brain Injury 4: 289-295.

28 Delargy M, Parry H, Burt A (1988) Quadriplegic care: an assessment of the impact on the carer. Int Disabil Stud 10: 145-147.

29 Mauss-Clum N, Ryan M (1981) Brain injury and the family. J Neurosurg Nurs 13: 165-169. 
30 Kester BL, Rothblum ED, Lobato D, Milhous RL (1988) Spouse adjustment to spinal cord injury: long term medical and psychosocial factors. Rehabil Counsel Bull 32: 4-21.

31 Nosek MA, Parker RM, Larsen S (1987) Psychosocial independence and functional abilities: their relationship in adults with severe musculoskeletal impairments. Arch Phys Med Rehabil 68: 840-845.

32 Davidoff G, Thomas P, Johnson M et al (1988) Closed head injury in acute traumatic spinal cord injury: incidence and risk factors. Arch Phys Med Rehabil 69: 869-872.

33 Roth E, Davidoff G, Thomas P et al (1989) A controlled study of neuropsychological deficits in acute spinal cord injury patients. Paraplegia 27: 480-489.

34 Davidoff G, Roth EJ, Richards JS (1992) Cognitive deficits in spinal cord injury: epidemiology and outcome. Arch Phys Med Rehabil 73: 275-284.

35 Henderson S, Duncan-Jones P, Byrne DG, Scott R (1980) Measuring social relationships: The (ISSI) Interview Schedule for Social Interaction. Psychol Med 10: 723-734.

36 Henderson S, Byrne DG, Duncan-Jones P (1981) Neurosis and the Social Environment. Academic Press, Sydney.

37 Elsass L, Kinsella G (1987) Social interaction following severe closed head injury. Psychol Med 17: 67-78.

38 Mackelprang RW, Hepworth DW (1987) Ecological factors in rehabilitation of patients with severe spinal cord injuries. Soc Work Health Care 13: 23-38.

39 Weissman MM, Sholomskas D, John K (1981) The assessment of social adjustment -an update. Arch Gen Psychiatry 38: 1250-1258.

40 Henderson S (1981) Social relationships, adversity and neurosis: an analysis of prospective observation. Br J Psychiatry 138: 391-399.

41 Duncan-Jones P (1981) The structure of social relationships: analysis of a survey instrument. Part 1. Soc Psychiatry 16: 55-61.

42 Snaith RP, Bridge GWK, Hamilton M (1976) The Leeds Scale for the Self Assessment of Anxiety and Depression. Br J Psychiatry 128: 156-165.

43 Kinsella G, Moran C, Ford B, Ponsford J (1988) Emotional disorder and its assessment within the severe head injured population. Psychol Med 18: 57-63.

44 Snaith RP, Bridge GWK, Hamilton M (1977) Manual for the Leeds Scales for the Self Assessment of Anxiety and Depression. Psychological Test Publications, Barnstaple, Devon.

45 Livingston M, Brooks DN, Bond MR (1985) Three months after severe head injury: psychiatric and social impact on relatives. J Neurol Neurosurg Psychiatry 48: 870-875.

46 Tyerman AD, Humphrey M (1984) Changes in self concept following severe head injury. Int J Rehabil Res 7: 11-23.

47 Livingston M, Brooks DN, Bond MR (1985) Patient outcome in the year following severe head injury and relatives' psychiatric and social functioning. J Neurol Neurosurg Psychiatry 48: 876-881.

48 Livingston M (1987) Head injury - the relatives' response. Brain Injury 1: 33-39.

49 Schulz R, Decker S (1985) Long term adjustment to physical disability-the role of social support, perceived control and self blame. J Personality Soc Psychol 48: 1162-1172.

50 Snaith RP, Constantopoulous AA, Jardine MY, McGuffin P (1978) A clinical scale for the self assessment of irritability. Br J Psychiatry 132: 164-171.

51 Woolsey RM (1985) Rehabilitation outcome following spinal cord injury. Arch Neurol 42: 116-119.

52 Yarkony GM, Roth EJ, Heinemann AW, Lovell L (1988) Rehabilitation outcomes in C6 tetraplegia. Paraplegia 26: 177-185.

53 Yarkony GM, Roth E, Lovell L et al (1988) Rehabilitation outcomes in complete C5 quadriplegia. $A M J$ Phys Med Rehabil 67: 73-76.

54 Drewes AR, Olsson AT, Slot O, Andreasen A (1989) Rehabilitation outcome for patients with spinal cord injury. Int Disabil Stud 11: 178-180.

55 Yarkony GM, Roth EJ, Meyer PR et al (1990) Rehabilitation outcomes in patients with complete thoracic spinal cord injury. Am J Phys Med Rehabil 69: 23-27.

56 Hammell KW (1994) Spinal Cord Injury Rehabilitation. Chapman and Hall, London.

57 Peters LC, Stambrook M, Moore AD, Esses L (1990) Psychosocial sequelae of closed head injury: effects on the marital relationship. Brain Injury 4: 39-47.

58 Cogswell B, (1968) Self socialization: readjustment of paraplegics in the community. J Rehabil 34: 11-13, 35.

59 Trieschmann RB (1988) Spinal Cord Injuries. Psychological, Social and Vocational Rehabilitation, 2 nd edn. Demos Publications, New York.

60 De Vivo MJ, Richards JS (1992) Community reintegration and quality of life following spinal cord injury. Paraplegia 30: 108-112.

61 Jongbloed L, Crichton A (1990) A new definition of disability: implications for rehabilitation practice and social policy. Can J Occup Ther 57: 32-38.

62 Swain J, Finkelstein V, French S, Oliver M (1993) Disabling Barriers-Enabling Environments. The Open University and Sage Publications, London. 